\title{
The Elasticity of Substitution across Maturities in International Capital Markets: A Simple Test
}

\author{
Konstantinos Drakos \\ University of Patras
}

\begin{abstract}
The paper tests the hypothesis of a maturity-independent foreign exchange risk premium or equivalently of a constant elasticity of substitution of international assets across the maturity spectrum. The empirical findings indicate that elasticity of substitution is indeed a function of maturity. In addition, the premia are found to be a monotonic function of the maturity distance between assets.
\end{abstract}

- JEL Classifications: C32, E43, F3, G15

- Key words: Elasticity of Substitution, Risk Premium, Expectations Hypothesis, Term Structure

\section{Introduction}

The issue of international asset substitutability is of major concern for policy makers and practitioners operating in the foreign exchange market. Furthermore, the asset substitutability across the maturity spectrum is of equal importance since it places the issue in a dynamic context. Initially, international asset substitutability was viewed in the light of the hypothesis of uniform substitutability (Porter, 1971). It was after a decade until the actual hypothesis was tested. In the context of the Covered Interest Rate Parity theorem a number of researchers investigated the possibility that the term structure of the forward premium was consistent with the Expectations Hypothesis (Hakkio, 1981; Baillie and MacMahon, 1985; Hakkio and Leiderman, 1986; Lippens, 1987; Boughton, 1988; MacDonald and Taylor, 1990; Jorion, 1992; Clarida and Taylor, 1997).

\footnotetext{
*Corresponding address: Konstantinos Drakos, Department of Economics, University of Patras, Rio, 26504, Patras, Greece, E-mail: kdrakos@upatras.gr

(C2005-Center for International Economics, Sejong Institution, All Rights Reserved.
} 
The present study will focus on the foreign exchange market risk premium's behaviour across the maturity spectrum. The hypothesis of maturity-independent elasticity of substitution is tested against the alternative that it is maturitydependent. In other words, it will be tested whether the magnitude of the risk premium is uniform across the maturity spectrum.

Ex ante deviations from the Uncovered Interest Rate Parity (UIRP), across the term structure, apart from the foreign exchange risk premium, represent term structure risk as well (Drakos, 2003). The main objectives of this study is to estimate the ex ante differential term premia across the short end of the maturity spectrum and analyse their statistical profile in order to assess whether elasticity of substitution is maturity-dependent.

\section{The Term Structure of Deviations from the UIRP}

Without loss of generality assume a two-period framework with a representative agent maximising her expected discounted lifetime (over the two periods) utility, where if arbitrage opportunities are to ruled out at time period $t$ (the time of decision making) the following should hold in ex-ante terms (Kaminsky and Peruga, 1990; Ayuso and Restoy, 1996; Abel, 1999):

$$
\begin{aligned}
& E_{t}\left\{\left[\frac{S_{t+2}}{S_{t}}\left(1+r_{t, 2}\right)^{2}-\left(1+r_{t, 2}^{*}\right)^{2}\right] M_{t+2,2}\right\}=0 \\
& E_{t}\left\{\left[\frac{S_{t+2}}{S_{t}}\left(1+r_{t, 1}\right)-\left(1+r_{t, 1}^{*}\right)\right] M_{t+1,1}\right\}=0 \\
& E_{t} E_{t+1}\left\{\left[\frac{S_{t+2}}{S_{t+1}}\left(1+r_{t+1,1}\right)-\left(1+r_{t+1,1}^{*}\right)\right] M_{t+2,1}\right\}=0
\end{aligned}
$$

Where,

$E_{t}=$ the expectations operator conditional on information available at time $t$

$S_{t}=$ the nominal bilateral exchange rate at period $t$

$r_{i, t}=$ the nominal spot interest rate for maturity $i$ at time $t$ (asterisk denotes foreign variables)

$M_{t+i, j}=$ the pricing kernel to be realised at period $t+i$, and $j$ is the time span of the kernel ${ }^{1}$.

The timing assumed is of the following form: 0 denotes the beginning of the 
first period (the time of the decision making), 1 denotes the beginning of the second period and finally 2 denotes the end of the second period (the terminal state).

In order to obtain closed form representations for equations 1 to 3 , one needs to make a distributional assumption. Assuming conditional log-normality and approximate $\ln (1+r)$ by $r$ we obtain (Engel, 1996):

$$
\begin{aligned}
& E_{t}\left(\Delta s_{2,0}\right)-2\left(r_{t, 2}-r_{t, 2}^{*}\right)=-\frac{1}{2} \operatorname{Var}_{t}\left(\Delta s_{2,0}\right)-\operatorname{Cov}_{t}\left(\Delta s_{2,0}, M_{t+2,2}\right)=0 \\
& E_{t}\left(\Delta s_{1,0}\right)-2\left(r_{t, 1}-r_{t, 1}^{*}\right)=-\frac{1}{2} \operatorname{Var}_{t}\left(\Delta s_{1,0}\right)-\operatorname{Cov}_{t}\left(\Delta s_{1,0}, M_{t+1,1}\right)=0 \\
& E_{t}\left(\Delta s_{2,1}\right)-2\left(r_{t+1,1}-r_{t+1,1}^{*}\right)=-\frac{1}{2} \operatorname{Var}_{t}\left(\Delta s_{1,0}\right)-\frac{1}{2} \operatorname{Var}_{t}\left(r_{t+1,1}-t_{t+1,1}^{*}\right) \\
& -\operatorname{Cov}_{t}\left(\Delta s_{2,1}, M_{t+2,1}\right)+\operatorname{Cov}_{t}\left(r_{t+1,1}-t_{t+1,1}^{*}\right)=0
\end{aligned}
$$

Where,

$D s_{i, j}=$ the change in logarithm of the exchange rate between periods $i$ and $j$.

$\operatorname{Var}_{t}, \operatorname{Cov}_{t}=$ the conditional on information $t$ variance and covariance respectively.

In the above equations, the variance terms appear due to Jensen Inequality and usually are negligible. The covariance terms (with the pricing kernel), however, are of great significance since they represent ex-ante premia.

In particular, the covariation of exchange rate changes with the pricing kernel represents the ex-ante foreign exchange risk premium (Engel, 1996). Similarly, the covariation of the interest rate with the pricing kernel represents the ex ante term (or liquidity) premium (Bekaert and Hodrick, 2000). In fact, in the present context, since the covariance is in terms of the interest spread, captures the difference between the domestic and foreign bond markets' term premia that actually price the differences in the maturity profile of the assets that are denominated in different currencies (Svensson, 1993; Bekaert and Hodrick, 2000; Drakos, 2003). Obviously equations 1 to 3 represent the ex-ante deviations from three investment strategies. In particular, equation 1 describes the deviation from a two-period buy-and-hold strategy in terms of the UIRP. Equations 2 and 3 taken together (sum) represent the ex-ante deviation form a two-period rollover strategy again in terms of the UIRP.

\footnotetext{
${ }^{1}$ What consists of the pricing kernel is not of particular importance in the present context, since we are not interested in explicitly testing a particular asset pricing paradigm. In general, it could represent the intertemporal marginal rate of substitution of consumption as in Lucas, (1982). Alternatively, it could be identified as the rate of return on the market portfolio.
} 
Since the two alternative strategies span the same investment horizon (in terms of maturity) their ex-ante deviations should be equal if arbitrage opportunities do not exist. Algebraically this statement is ${ }^{2}$ :

$$
E_{t}\left(\Delta s_{2,0}\right)-2\left(r_{t, 2}-r_{t, 2}^{*}\right)-\left[E_{t}\left(\Delta s_{1,0}\right)-\left(r_{t, 1}-r_{t, 1}^{*}\right)+E_{t}\left(\Delta s_{2,1}\right)-\left(r_{t+1,1}-t_{t+1,1}^{*}\right)\right]=0
$$

Or equivalently

$$
\begin{aligned}
& -\operatorname{Cov}_{t}\left(\Delta s_{2,0}, M_{t+2,2}\right)-\left[-\operatorname{Cov}_{t}\left(\Delta s_{1,0}, M_{t+1,1}\right)-\operatorname{Cov}_{t}\left(\Delta s_{2,1}, M_{t+2,1}\right)\right] \\
& =-\operatorname{Cov}_{t}\left(r_{t+1,1}-t_{t+1,1}^{*}, M_{t+1,1}\right)
\end{aligned}
$$

Equation 8 simply states that in the absence of arbitrage opportunities there is a link between the term structure of ex-ante UIRP deviations and the term structures of the two bond markets. It clearly shows that the term structure of the foreign exchange risk premia is equal to the differential term premia. In other words, whether the two period ('long-horizon') risk premium is an average of the two one period ('short-horizon') risk premia depends on whether the Expectations Hypothesis (EH) is an adequate characterisation of the two bond markets involved. In fact, one may conclude by simply observing equation (8) that the term structure of the foreign exchange market risk premia will be consistent with the Expectations Hypothesis (that is will be maturity independent) in either of the two cases: either the term premia in both bond markets are identically zero, or they must be of equal absolute magnitude and effectively cancel each other out. The first corresponds to the case where the strong form of the Expectations Hypothesis (term premia equal to zero) holds for both bond markets, whereas the second case when a restricted weak (term premia non-zero but of equal magnitude) form holds.

Thus, what eq. 8 suggests is that there is a mapping of the properties of the combined term structure (the linear combination of the two term structures) on the properties of the risk premium's term structure. If one wants to empirically test whether the foreign exchange risk premium is maturity independent simply has to test whether the combined term structure of interest rates conforms to the $\mathrm{EH}$. If it turns out that the dynamic path of the combined term structure of cross-currency interest rate differentials is consistent with the EH then one has evidence in favour of maturity independent foreign exchange market risk premium or equivalently that the magnitude of the risk premium is uniform across maturities. In contrast, if the

${ }^{2}$ In order to derive equation 8 we have used the fact that the variances of the exchange rate changes cancel each other out. The variance of the interest rate spread has been ignored for expositional reasons. 
combined term structure deviates from the discussed benchmark then there is evidence for a maturity dependent risk premium and a differing degree of substitutability across the maturity spectrum. In fact, one can conclude that the foreign exchange market risk premium will be maturity-independent in either of the two cases,

- When the term premium is zero in both bond markets, or

- When term premia in the two markets are of equal absolute magnitude and effectively cancel each other out.

Thus, if one wants to empirically test whether the risk premium is adequately described by the Expectations Hypothesis one simply has to test whether differential term premia are zero on average. If it turns out that the average differential term premia are zero then one has evidence in favour of maturity independent foreign exchange market risk premium or equivalently that the magnitude of the risk premium is uniform across maturities. In contrast, if they are non-zero on average then there is evidence for a maturity-dependent risk premium and ultimately a differing substitutability across the maturity spectrum. Therefore, there are two distinct possibilities for the risk premium across maturities.

$$
\text { If } E\left(t p_{1 t}^{*}-t p_{1 t}\right)=0 \Rightarrow R P=c
$$

Where $\mathrm{c}$ is a constant. The other possibility is:

$$
\text { If } E\left(t p_{1 t}^{*}-t p_{1 t}\right) \neq 0 \Rightarrow R P=f(m)
$$

Where $\mathrm{m}$ stands for maturity.

Equation 10 states that if the mean differential term premia are non-zero then this implies that the magnitude of the risk premium varies across maturities or equivalently that the elasticity of substitution is maturity dependent (a function $f$ of maturity). So, a way to test whether the risk premium is maturity dependent is simply to test whether the 'national' term premia are homogeneous (of equal magnitude) across the term structure.

\section{Data}

The dataset consists of Eurodollar, Eurosterling, Euromark, and Eurocanadian Dollar nominal interest rates for the following maturities: 1-month, 3-month, 6- 
month, and 12-month. We also collected bilateral exchange rates for the pairs of countries. The data are seasonally unadjusted end of month values and start from November 1988 and end at November 1998. The Bank of International Settlements kindly supplied the data set. The price (CPI) and industrial production indices were taken from the IFS's CD-ROM.

\section{Empirical Results}

\section{A. Estimating the Premia}

Following Wolff, (1987) and Nijman and Wolff, (1993), it is convenient to refer to the premia component of the ex post deviation from the UIRP as the signal that is of interest, and the rest as noise that is added to the signal. Assuming rational expectations constraints the forecast errors to be uncorrelated with elements belonging to the conditioning information set and also being stochastic processes which are "well behaved". These properties of the forecast errors provide a straightforward way of estimating the ex ante premia, often called the Data-based or Projection approach (Cumby, 1988; Canova and Marrinan, 1993; Mishkin, 1993; Solnik, 1993; Ilmanen, 1995). The Projection approach basically consists of regressing the ex post quantity on a set of variables, which were known at the time of the decision making (elements of the conditioning information set) in order to test whether these variables have any explanatory power. Basically, under the truth of rational expectations the forecast error should be uncorrelated with the elements of the information set. Therefore, projecting the ex post excess return differential on this set will help distinguish the systematic part from the unsystematic. The systematic part is represented by the fitted values of the regression that can serve as a proxy for the differential term premia (Cumby, 1988). The unsystematic part (residuals) represents the "pure" forecast error which error is unforecastable in ex ante terms.

The ex post deviation from the UIRP was constructed for the two alternative investment strategies (Buy-and-Hold, and Rollover). Then ex post excess return differentials (EXD) were calculated. Then it was projected on the set of domestic regressors ${ }^{3}$, which included the differenced inflation rate (INF) lagged one period, the differenced change in industrial production (IP), the slope of the yield curve (TSS) and the excess return (EXD) lagged (one period or two periods in some

\footnotetext{
${ }^{3}$ The correlation matrix of the regressors is not reported here for brevity but is available on request.
} 
cases). Additionally, we allow for an Autoregressive part in the empirical specification. The regressions do not represent an attempt to get the best fit, and this is reflected in the fact that the instruments were included in the regression not because of their statistical significance (in some cases they are statistically insignificant) but rather for methodological reasons.

The ex post deviations have been estimated by using overlapping data, so the error term follows a Moving Average process ${ }^{4}$. This information has been explicitly taken into account in the estimation process by imposing the restriction that the error term follows the particular MA process needed. Note that the task here is not to conduct inference about the instruments' significance nor their impact on the ex post deviation but rather to extract the systematic part of it, thus, taking into account the exact (meaning the correct) parametric form of the error process is more appropriate. Another way to view this, is to recognise that the data by their measurement have information in the error structure, which needs to be uncovered. Without this adjustment, the regressions would have been misspecified and the fitted values (representing premia) would not be a good approximation of the 'true' variable $^{5}$. The estimation involved the following linear projections:

$$
E X D_{k}=\beta_{1}(I N F)_{t-13}+\beta_{2}(I P)_{t-13}+\beta_{3}\left(T S S_{k}\right)_{t-12}+\sum_{i=1}^{2} \phi_{i} E X D_{t-i}+\varepsilon_{t}-\sum_{i=1}^{q} \theta_{i} \varepsilon_{t-i}
$$

Where $k$ denotes the 12-3 and the 12-6 cases, and $q=5$ for the former and $q=8$ for the latter.

$$
E X D_{k}=\beta_{1}(I N F)_{t-7}+\beta_{2}(I P)_{t-7}+\beta_{3}\left(T S S_{k}\right)_{t-6}+\sum_{i=1}^{2} \phi_{i} E X D_{t-i}+\varepsilon_{t}-\sum_{i=1}^{q} \theta_{i} \varepsilon_{t-i}
$$

Where $k$ denotes the 6-3 case, and $q=2$.

Tables 1 and 2 summarise the regression results for the excess returns

\footnotetext{
${ }^{4}$ The error term in each case follows a MA (n-m-1) process. Where, $n$ and $m$ are the maturity of the longterm and the short-term asset respectively.

${ }^{5}$ The need for ML estimation (MA specification for the error term), was apparent also from preliminary OLS regressions, where they exhibited low fit and the residuals did not pass the diagnostics. By employing the MA alternative, fit improved dramatically, residuals were whitened, and in the vast majority of the cases the coefficients of the MA terms were highly significant. All these can be interpreted as providing evidence for the 'superiority' of the estimation method chosen.
} 
Table 1. Pound Sterling against DM*

\begin{tabular}{|c|c|c|c|}
\hline Regressors & BP/DM123 & BP/DM126 & BP/DM63 \\
\hline \multirow{2}{*}{$\Delta(\mathrm{INF})_{-\mathrm{j}}$} & -0.158 & -0.101 & 0.029 \\
\hline & $(-2.54)$ & $(-2.3)$ & $(1.01)$ \\
\hline \multirow{2}{*}{$\Delta(\mathrm{PRO})_{-\mathrm{j}}$} & 0.0121 & 0.027 & -0.0169 \\
\hline & $(1.14)$ & $(2.46)$ & $(-1.41)$ \\
\hline \multirow{2}{*}{$(\mathrm{TSSij})_{-(\mathrm{j}-1)}$} & 0.849 & 0.973 & 0.639 \\
\hline & $(11.22)$ & (15.31) & $(4.91)$ \\
\hline \multirow{2}{*}{$\left(\mathrm{EXDij}_{-1}\right.$} & 0.2132 & 0.119 & \multirow{2}{*}{ - } \\
\hline & $(2.96)$ & $(2.1)$ & \\
\hline \multirow{2}{*}{ MA(1) } & 0.9 & 0.795 & 0.85 \\
\hline & (12.91) & $(15.92)$ & (11.23) \\
\hline \multirow{2}{*}{$\mathrm{MA}(2)$} & 0.612 & 0.529 & 0.56 \\
\hline & (13.53) & (38.77) & $(8.23)$ \\
\hline \multirow{2}{*}{ MA(3) } & 0.578 & 0.593 & \multirow{2}{*}{ - } \\
\hline & (6.63) & $(12.04)$ & \\
\hline \multirow{2}{*}{ MA(4) } & 0.8 & 0.688 & \multirow[b]{2}{*}{ - } \\
\hline & (20.07) & $(49.75)$ & \\
\hline \multirow{2}{*}{ MA(5) } & 0.979 & 0.8 & \multirow{2}{*}{-} \\
\hline & (21.87) & (14.51) & \\
\hline \multirow{2}{*}{ MA(6) } & 0.548 & 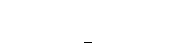 & \multirow{2}{*}{-} \\
\hline & $(13.94)$ & - & \\
\hline \multirow{2}{*}{ MA(7) } & 0.041 & & \multirow{2}{*}{-} \\
\hline & $(0.45)$ & - & \\
\hline \multirow{2}{*}{ MA(8) } & 0.025 & - & \multirow{2}{*}{ - } \\
\hline & $(0.24)$ & - & \\
\hline $\mathrm{R}^{2}$-adjusted & 0.727 & 0.732 & 0.511 \\
\hline s.e of regression & 0.278 & 0.224 & 0.2 \\
\hline F-statistic & 26.49 & 36.94 & 30.1 \\
\hline DW & 1.72 & 1.49 & 1.72 \\
\hline
\end{tabular}

*The numbers in the parentheses are the heteroskedasticity-adjusted (White) t-statistics. The index $\mathrm{j}$ is equal to 13 for the 12-3 and 12-6 regressions and equal to 7 for the 6-3 regressions.

denominated in Pound Sterling.

Since the goal of the projections is to measure the ex ante differential term premia, no attempt is made to comment on the regressions' results. However, the way regressors (information set) affect the ex post deviations is compatible with our theoretical priors. Tables 3 and 4 summarise the regression results for the excess returns denominated in Deutsche Mark. 
Table 2. Pound Sterling against US Dollar*

\begin{tabular}{|c|c|c|c|}
\hline Regressors & BP/USD123 & BP/USD126 & BP/USD63 \\
\hline$\Delta(\mathrm{INF})_{-\mathrm{j}}$ & $\begin{array}{c}-0.0044 \\
(-0.45)\end{array}$ & $\begin{array}{c}-0.046 \\
(-0.642)\end{array}$ & $\begin{array}{c}0.108 \\
(-3.64)\end{array}$ \\
\hline$\Delta(\mathrm{PRO})_{-\mathrm{j}}$ & $\begin{array}{l}-0.008 \\
(-0.33)\end{array}$ & $\begin{array}{l}0.0012 \\
(0.053)\end{array}$ & $\begin{array}{l}-0.014 \\
(-1.46)\end{array}$ \\
\hline$(\mathrm{TSSij})_{-(\mathrm{j}-1)}$ & $\begin{array}{c}0.56 \\
(5.43)\end{array}$ & $\begin{array}{l}0.851 \\
(7.67)\end{array}$ & $\begin{array}{c}0.68 \\
(5.25)\end{array}$ \\
\hline$\left(\mathrm{EXDij}_{-1}\right.$ & $\begin{array}{c}0.52 \\
(4.94)\end{array}$ & $\begin{array}{l}0.387 \\
(3.05)\end{array}$ & - \\
\hline$\left(\mathrm{EXDij}_{-2}\right.$ & - & - & - \\
\hline MA(1) & $\begin{array}{l}0.741 \\
(6.51)\end{array}$ & $\begin{array}{c}0.76 \\
(4.91)\end{array}$ & $\begin{array}{c}1.158 \\
(16.73)\end{array}$ \\
\hline $\operatorname{MA}(2)$ & $\begin{array}{c}0.134 \\
(1.1)\end{array}$ & $\begin{array}{l}0.335 \\
(2.36)\end{array}$ & $\begin{array}{c}0.816 \\
(15.39)\end{array}$ \\
\hline $\operatorname{MA}(3)$ & $\begin{array}{l}-0.166 \\
(-1.54)\end{array}$ & $\begin{array}{l}0.0543 \\
(0.406)\end{array}$ & - \\
\hline $\operatorname{MA}(4)$ & $\begin{array}{c}0.018 \\
(0.145)\end{array}$ & $\begin{array}{l}0.128 \\
(1.01)\end{array}$ & - \\
\hline $\operatorname{MA}(5)$ & $\begin{array}{l}0.427 \\
(3.78) \\
\end{array}$ & $\begin{array}{l}0.282 \\
(3.01)\end{array}$ & - \\
\hline $\operatorname{MA}(6)$ & $\begin{array}{l}0.308 \\
(2.98)\end{array}$ & - & - \\
\hline $\operatorname{MA}(7)$ & $\begin{array}{l}-0.0056 \\
(-0.066)\end{array}$ & - & - \\
\hline $\operatorname{MA}(8)$ & $\begin{array}{c}-0.043 \\
(-0.415)\end{array}$ & - & - \\
\hline $\mathrm{R}^{2}$-adjusted & 0.788 & 0.74 & 0.68 \\
\hline s.e of regression & 0.395 & 0.34 & 0.24 \\
\hline F-statistic & 36.56 & 39.45 & 61.61 \\
\hline DW & 1.78 & 1.69 & 1.95 \\
\hline
\end{tabular}

*The numbers in the parentheses are the heteroskedasticity-adjusted (White) t-statistics. The index $\mathrm{j}$ is equal to 13 for the 12-3 and 12-6 regressions and equal to 7 for the 6-3 regressions.

\section{B. Elasticity of Substitution}

The systematic parts from the above projections were used as a proxy for the conditional differential term premia. It should be noted that when investigating the properties of the differential term premia one has to be cautious since by 
Table 3. Deutsche Mark against Canadian Dollar*

\begin{tabular}{|c|c|c|c|}
\hline Regressors & DM/CD123 & $\mathrm{DM} / \mathrm{CD} 126$ & DM/CD63 \\
\hline$\Delta(\mathrm{INF})_{-\mathrm{j}}$ & $\begin{array}{l}0.082 \\
(0.43)\end{array}$ & $\begin{array}{c}-0.14 \\
(-1.55)\end{array}$ & $\begin{array}{l}0.013 \\
(0.18)\end{array}$ \\
\hline$\Delta(\mathrm{PRO})_{-\mathrm{j}}$ & $\begin{array}{c}-0.29 \\
(-2.13)\end{array}$ & $\begin{array}{l}0.016 \\
(1.13)\end{array}$ & $\begin{array}{l}-0.002 \\
(-0.24)\end{array}$ \\
\hline$(\mathrm{TSSij})_{-(\mathrm{j}-1)}$ & $\begin{array}{l}0.155 \\
(0.6)\end{array}$ & $\begin{array}{c}0.4 \\
(1.32)\end{array}$ & $\begin{array}{l}0.734 \\
(2.21)\end{array}$ \\
\hline$(\text { EXDij })_{-1}$ & $\begin{array}{c}0.6 \\
(2.01)\end{array}$ & $\begin{array}{c}0.722 \\
(3.73)\end{array}$ & - \\
\hline$(\text { EXDij })_{-2}$ & - & $\begin{array}{c}-0.386 \\
(-2.1)\end{array}$ & - \\
\hline MA(1) & $\begin{array}{l}0.539 \\
(2.01)\end{array}$ & $\begin{array}{l}0.075 \\
(0.35)\end{array}$ & $\begin{array}{c}0.861 \\
(15)\end{array}$ \\
\hline MA(2) & $\begin{array}{l}0.426 \\
(1.38)\end{array}$ & $\begin{array}{l}0.616 \\
(5.76)\end{array}$ & $\begin{array}{l}0.687 \\
(7.43)\end{array}$ \\
\hline MA(3) & $\begin{array}{c}0.008 \\
(0.028)\end{array}$ & $\begin{array}{l}0.476 \\
(4.57)\end{array}$ & - \\
\hline MA(4) & $\begin{array}{c}0.314 \\
(1.62)\end{array}$ & $\begin{array}{l}0.289 \\
(2.53)\end{array}$ & - \\
\hline $\mathrm{MA}(5)$ & $\begin{array}{c}0.06 \\
(0.28)\end{array}$ & $\begin{array}{l}0.136 \\
(1.46)\end{array}$ & - \\
\hline MA(6) & $\begin{array}{l}-0.084 \\
(-0.47)\end{array}$ & - & \\
\hline MA(7) & $\begin{array}{l}0.248 \\
(1.87)\end{array}$ & - & - \\
\hline $\operatorname{MA}(8)$ & $\begin{array}{l}0.063 \\
(0.64)\end{array}$ & - & - \\
\hline $\mathrm{R}^{2}$-adjusted & 0.7 & 0.66 & 0.577 \\
\hline s.e of regression & 0.46 & 1.38 & 0.35 \\
\hline F-statistic & 23.91 & 24.09 & 39.2 \\
\hline DW & 1.97 & 1.9 & 1.82 \\
\hline
\end{tabular}

*The numbers in the parentheses are the heteroskedasticity-adjusted (White) t-statistics. The index $\mathrm{j}$ is equal to 13 for the 12-3 and 12-6 regressions and equal to 7 for the 6-3 regressions.

construction they are the difference between two premia arising from different term structures $^{6}$. Tables 5 and 6 report the mean differential term premia in the two currencies and their t-statistics (testing the null of zero means).

The null hypothesis of zero-mean differential term premia essentially 
Table 4. Deutsche Mark against US Dollar*

\begin{tabular}{|c|c|c|c|}
\hline Regressors & DM/USD123 & DM/USD126 & DM/USD63 \\
\hline$\Delta(\mathrm{INF})_{-\mathrm{j}}$ & $\begin{array}{l}-0.057 \\
(-0.56)\end{array}$ & $\begin{array}{l}-0.093 \\
(-2.89)\end{array}$ & $\begin{array}{l}-0.011 \\
(-0.29)\end{array}$ \\
\hline$\Delta(\mathrm{PRO})_{-\mathrm{j}}$ & $\begin{array}{c}0.0005 \\
(0.04)\end{array}$ & $\begin{array}{l}0.014 \\
(1.81)\end{array}$ & $\begin{array}{c}0.0012 \\
(0.2)\end{array}$ \\
\hline$(\mathrm{TSSij})_{-(\mathrm{j}-1)}$ & $\begin{array}{l}-0.064 \\
(-2.83)\end{array}$ & $\begin{array}{c}-0.026 \\
(-0.6)\end{array}$ & $\begin{array}{l}0.207 \\
(1.47)\end{array}$ \\
\hline$\left(\right.$ EXDij $_{-1}$ & $\begin{array}{c}0.97 \\
(72.57)\end{array}$ & $\begin{array}{c}1.51 \\
(17.84)\end{array}$ & $\begin{array}{l}0.316 \\
(2.21)\end{array}$ \\
\hline$\left(\mathrm{EXDij}_{-2}\right.$ & - & $\begin{array}{c}-0.612 \\
(-7.6)\end{array}$ & $\begin{array}{l}-0.276 \\
(-2.28)\end{array}$ \\
\hline MA(1) & $\begin{array}{l}0.008 \\
(0.06)\end{array}$ & $\begin{array}{c}-0.35 \\
(-4.06)\end{array}$ & $\begin{array}{l}0.629 \\
(6.43)\end{array}$ \\
\hline MA(2) & $\begin{array}{l}-0.276 \\
(-2.7)\end{array}$ & $\begin{array}{c}-0.4 \\
(-5.84)\end{array}$ & $\begin{array}{l}0.722 \\
(8.39)\end{array}$ \\
\hline MA(3) & $\begin{array}{l}-0.448 \\
(-4.29)\end{array}$ & $\begin{array}{c}-0.35 \\
(-5.82)\end{array}$ & - \\
\hline MA(4) & $\begin{array}{l}-0.06 \\
(-0.5)\end{array}$ & $\begin{array}{c}0.11 \\
(1.226)\end{array}$ & - \\
\hline $\operatorname{MA}(5)$ & $\begin{array}{l}0.077 \\
(0.69)\end{array}$ & $\begin{array}{c}0.63 \\
(8.29)\end{array}$ & - \\
\hline MA(6) & $\begin{array}{c}-0.14 \\
(-1.21)\end{array}$ & - & - \\
\hline $\operatorname{MA}(7)$ & $\begin{array}{l}-0.057 \\
(-0.53)\end{array}$ & - & - \\
\hline MA(8) & $\begin{array}{l}-0.065 \\
(-0.62)\end{array}$ & - & - \\
\hline $\mathrm{R}^{2}$-adjusted & 0.82 & 0.81 & 0.52 \\
\hline s.e of regression & 0.28 & 0.22 & 0.18 \\
\hline F-statistic & 44.56 & 51.99 & 21.81 \\
\hline DW & 1.97 & 2.23 & 1.88 \\
\hline
\end{tabular}

*The numbers in the parentheses are the heteroskedasticity-adjusted (White) t-statistics. The index $\mathrm{j}$ is equal to 13 for the 12-3 and 12-6 regressions and equal to 7 for the 6-3 regressions.

corresponds to the null of a maturity-independent risk premium or equivalently a constant elasticity of substitution across the maturity spectrum. The differential

${ }^{6}$ When premia in domestic bond markets are considered the typical assumption is that they are positive. In the present context, however, they may well be negative since they are the difference between two national premia. Therefore, the sign of their difference depends on their absolute magnitudes. 
Table 5. Estimated differential term premia in Pound Sterling*

\begin{tabular}{ccccccc}
\hline \multirow{2}{*}{ DTP } & BP/DM & BP/US & BP/DM & BP/US & BP/DM & BP/US \\
& 123 & 123 & 126 & 126 & 63 & 63 \\
\hline \multirow{2}{*}{ Mean DTP } & $15.1^{+}$ & $16^{-}$ & $11.5^{+}$ & $9.3^{-}$ & $2.2^{+}$ & $4.6^{-}$ \\
& $(3.21)$ & $(-2.11)$ & $(3.2)$ & $(-1.6)$ & $(1.07)$ & $(-1.32)$ \\
\hline
\end{tabular}

*The numbers in the parentheses are the t-statistics for the significance of the mean differential term premia. Premia are reported as basis points in annual terms. Mean Term Premia are reported in absolute values and the superscript denotes whether they were originally positive or negative.

Table 6. Estimated differential term premia in Deutsche Mark*

\begin{tabular}{ccccccc}
\hline \multirow{2}{*}{ DTP } & DM/US & DM/CD & DM/US & DM/CD & DM/US & DM/CD \\
& 126 & 126 & 123 & 123 & 63 & 63 \\
\hline \multirow{2}{*}{ Mean DTP } & $23-$ & $22-$ & $36.2-$ & $37.2-$ & $5.86-$ & $6.4-$ \\
& $(-4.74)$ & $(-4.15)$ & $(-6.15)$ & $(-5.04)$ & $(-2.86)$ & $(-1.74)$ \\
\hline
\end{tabular}

*The numbers in the parentheses are the t-statistics for the significance of the mean differential term premia. Premia are reported as basis points in annual terms. Mean Term Premia are reported in absolute values and the superscript denotes whether they were originally positive or negative

term premia are statistically significant for all pairs of bonds, at the maturities (126 ) and (12-3), whereas in the (6-3) maturities 2 out of four pairs are statistically insignificant from zero. Thus, the tests point to the rejection of the null, providing evidence for a maturity-dependent elasticity of substitution of international assets, contrary to the standard assumption of the UIRP.

\section{Monotonicity of Premia}

Having established the maturity-dependence of the elasticity of substitution another interesting exercise would be to investigate their behaviour across maturities. In particular, maturity-dependence implies that the foreign exchange market risk premium's term structure is not adequately described by the Expectations Hypothesis. Is it possible to characterise the degree of deviation from the Expectations Hypothesis benchmark across maturities? In other words, can one estimate the shape of the deviation from the EH?

The relationship among term premia has been the centre of a number of theories. A theory with well-established structure is the Liquidity Preference Hypothesis, which asserts that the term premium (Hicks, 1946), which places an a priori restriction that premia are monotonically increasing with maturity. For instance, in a set of premia the following should hold: 


$$
T P_{1}<T P_{2}<\ldots<T P_{n}
$$

The theory, as it becomes apparent, has a straightforward predictive content, which is easily testable. In our context, a modified version of the Liquidity Preference Hypothesis is relevant, that would imply that differential term premia satisfy a relationship in the form of (13). In order to make the point clearer, define $D$ as the (absolute) deviation of the risk premium's term structure form the benchmark of the Expectations Hypothesis. Also define $d$ as the distance of the assets' maturity date (their term to maturity). Now, if (13) was true for the differential term premia it would imply that:

and also that

$$
D=g(d)
$$

$$
\forall d_{2}>d_{1} \Leftrightarrow g\left(d_{2}\right)>g\left(d_{1}\right)
$$

Expression (14) states that $g(d)$ is a monotonic function of $d$. In other words, if the modified liquidity Preference Hypothesis is true for the differential term premia, then the deviation $(D)$ of the risk premium's term structure from the Expectations Hypothesis will be a function of the maturity distance $(d)$ of the assets involved. On the other hand if the differential term premia are rather equal across

\section{Graph 1.}

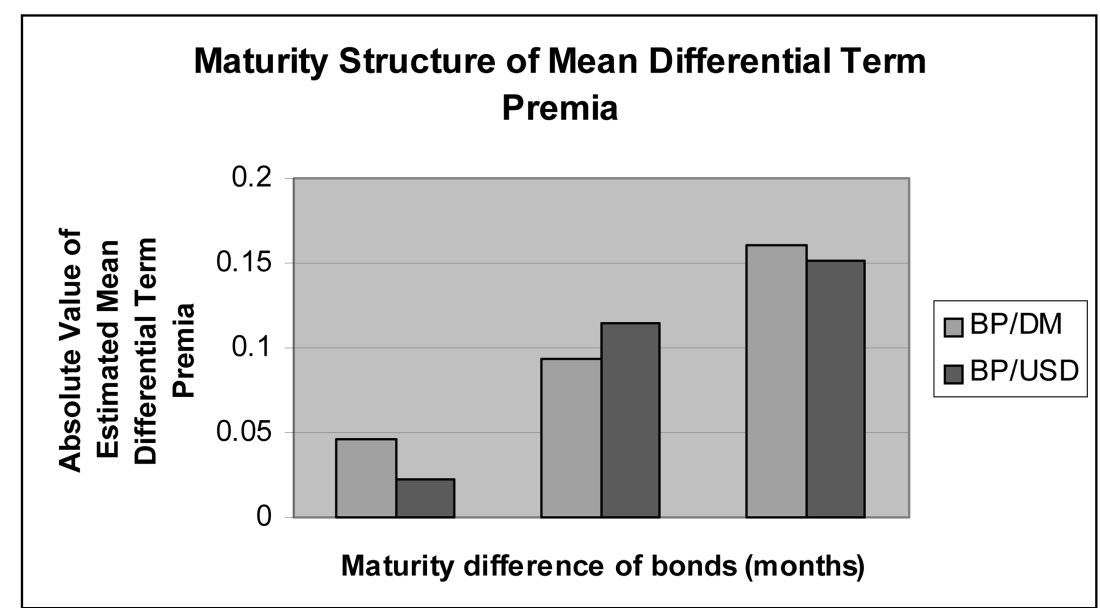

*The three data points depicted in both graphs correspond to the following: the first represents 3 periods of maturity difference, arising from the term to maturity of $6 \mathrm{vs}$ 3 -month bonds. The second point stands for the difference between 12 vs 6-month bonds, and the third for 12 vs 3-month bonds. So, the maturity difference starts from 3 periods, increasing to 6 and reaching its maximum at 9 . 


\section{Graph 2.}

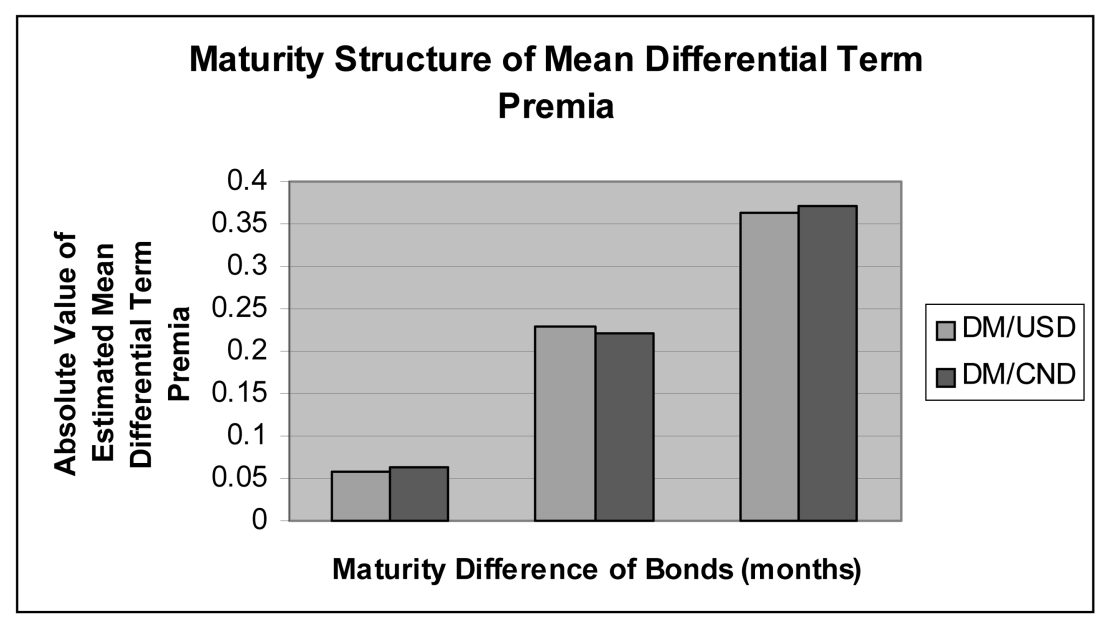

different segments of the maturity spectrum, then the deviation of the risk premium's term structure from the Expectations Hypothesis will be 'flat', or equivalently independent of the maturity distance of the assets involved. Graphs 1 and 2 illustrate the relationship between the absolute value of the estimated mean differential term premium and the difference in the maturity of the bonds.

Although, the visual inspection of the above graphs suggests that the differential term premium increases with the maturity difference of the bonds, this is a hypothesis that will be formally tested. Whether the term premium is monotonically increasing with maturity is an unsolved empirical issue. In the context of domestic money markets evidence for the monotonicity of premia has been widely reported (McCulloch, 1987; Richardson et al, 1992; Drakos, 2001). The only empirical study, which tests the relevant hypothesis for the foreign exchange market is by Giovannini (1980) who focuses on deviations from the Covered Interest Rate Parity along the term structure for maturities 1, 3, and 6 months. Giovannini, bases his study on the Wilcoxon Matched-Pairs Signed-Ranks test, and the finding is that agents have a preferred habitat depending on the currency studied. In the present study, following Giovannini, the Wilcoxon Matched-Pairs Signed-Ranks test will be employed. The Wilcoxon test is a non-parametric test and therefore surpasses the problem of specifying a particular distribution for the underlying population ${ }^{7}$

${ }^{7}$ t-tests are based on the 'suspicious' assumption of normality, which for financial data has been proved inadequate due to problems of 'fat-tailed' distributions. 
(Hettmanspencer, 1984). The Wilcoxon test is used to test the null that the two populations have identical distribution functions against the alternative that the two distributions differ only with respect to location (median), if at all. For large samples the Wilcoxon test statistic has an asymptotic distribution tending to normal.

The testing procedure will be the following: for each currency, the Wilcoxon test will be conducted for all possible pairs of term premia, namely the premium arising from the 12-3 month strategy against that from the 12-6 strategy. Then, that from 12-3 against that from the 6-3, and finally that from the 12-6 against that from the 63 strategy. The relevant statistics for the DM cases are reported in Table 7.

The test statistics point to the rejection of the null in every case supporting the hypothesis that the differential term premia both the DM/CD and DM/US cases are monotonically increasing with maturity. Thus, the finding is that premia are an increasing function of the difference in maturity between debt instruments.

Equivalently, this implies that the deviation of the risk premium's term structure form the Expectations Hypothesis is a monotonic function of the maturity distance between the assets. Therefore, the Deutsche Mark risk premium's term structure deviates from the Expectations Hypothesis monotonically with the distance of the assets. A way to interpret this finding would be that agents active in the DM/US and $\mathrm{DM} / \mathrm{CD}$ market exhibit a short maturity habitat and demand a higher term premium in order to be induced to 'lock' themselves in longer maturities. The shorter habitat can be justified by higher variability of their expectations. Uncertainty about the relative future path of interest rates causes a preference over shorter-lived assets, which becomes more severe as the maturity distance of the assets involved increases. Given that the underlying assets come from countries belonging to rather different geographic and economic areas (two North American and a European Union country), one would expect that money markets reflect the apparent differences in market fundamentals and also monetary policies. Table 8 reports the statistics for differential term premia denominated in Pound Sterling.

Table 7. Wilcoxon Matched-Pairs Signed-Ranks test for premia denominated in DM ${ }^{\mathrm{a}}$

\begin{tabular}{cll}
\hline Premia & DM/CD & DM/US \\
\hline $123-126$ & $-3.13^{* * *}$ & $-5.01^{* * * *}$ \\
\hline $123-63$ & $-4.24^{* * *}$ & $-4.54^{* * * *}$ \\
\hline $126-63$ & $-2.3^{* * * *}$ & $-2.63^{* * * *}$
\end{tabular}

a. The numbers reported are the Z-statistics. ${ }^{*},{ }^{* *}, * * *, * * * *$, denote rejection of the null at $10,5,2.5$, 1 percent respectively. 
Table 8. Wilcoxon Matched-Pairs Signed-Ranks test for premia denominated in Pound Sterling*

\begin{tabular}{ccc}
\hline Premia & BP/DM & BP/US \\
\hline $123-126$ & $-1.344^{*}$ & $-1.955^{* * *}$ \\
$123-63$ & $-2.148^{* * *}$ & $-1.283^{*}$ \\
$126-63$ & $-1.906^{* *}$ & -0.63 \\
\hline
\end{tabular}

a. The numbers reported are the Z-statistics. ${ }^{*}, * *, * * *, * * * *$, denote rejection of the null at $10,5,2.5$, 1 percent respectively.

In the $\mathrm{BP} / \mathrm{DM}$ case the statistics imply the following shape for the maturity structure of the differential term premia:

$$
\operatorname{DTP}_{3}^{12}=\operatorname{DTP}_{6}^{12}>\operatorname{DTP}_{3}^{6}
$$

In the $\mathrm{BP} / \mathrm{DM}$ case, the risk premium's term structure deviations from the benchmark do not exhibit monotonicity with respect to maturity distance between assets. Deviations seem to be fairly flat, bearing no relevance to the maturity distance of the assets. This could be justified by recognising the fact that we are dealing with two European Union countries' bond markets and therefore one would expect differences between the two money markets to be insignificant, given the undergoing convergence and uniform economic policies adopted. For the BP/ US case the statistics support the following shape for the differential term premia term structure:

$$
D T P_{3}^{12}>D T P_{6}^{12}=D T P_{3}^{6}
$$

The term structure of deviations again seem to be rather flat, suggesting that for the BP/US case bond market, they do not exhibit monotonicity with respect to the maturity distance of the assets.

All in all, for the term structure deviations of the risk premium in Pound Sterling the conclusion is that they are not monotonically increasing with maturity distance but seem rather 'flat'. For the BP/DM case, a possible reason is the fact that both countries are members of the European Union, which results in convergent money and bond markets, whereas for the $\mathrm{BP} / \mathrm{US}$ case a possible explanation seem to be the traditional link between the two economies.

\section{Conclusion}

Apart form the empirical evidence reported in this study a methodological 
contribution is also made. The analysis showed explicitly how one could account for the behaviour of the risk premium across the term structure. It shows that there exists a one to one mapping between the properties of the risk premium's term structure and that of the cross-currency interest rate spreads across maturities.

The paper's aim was to investigate the presence of a maturity-dependent foreign exchange market risk premium. In particular, we tested the hypothesis that the magnitude of the risk premium is maturity-independent or equivalently that the elasticity of substitution of international assets is constant across the maturity spectrum. Since the term structure of the foreign exchange risk premium does not conform to the Expectations Hypothesis, the null of constant elasticity of substitution was rejected providing evidence that the magnitude of the foreign exchange risk premium is a function of the assets' maturity.

Furthermore, an attempt was made to explore the properties of the risk premium's term structure deviations from the Expectations Hypothesis. The empirical findings suggest that for a number of cases the deviation from the benchmark is a function of the maturity distance of the assets involved. This finding, bears relevance to a modified version of the Hicksian Liquidity Preference Hypothesis. Further research could be directed towards explaining the above link within an explicit general equilibrium model. In addition, an interesting empirical extension would be to test whether the findings reported here are repeating themselves in longer maturities. Finally, a challenging theoretical matter would be to incorporate the role played by the monetary authorities, whose presence undoubtedly is strong both in the foreign exchange market and the domestic money markets.

\section{Acknowledgements}

I am grateful to Roy Bailey, Marcus Chambers and Carmen Li for their helpful comments on earlier drafts of the paper. All remaining errors and ambiguities are my responsibility.

Received 13 April 2004, Accepted 21 December 2004

\section{References}

Abel, A. (1999). Risk Premia and Term Premia in General Equilibrium, Journal of 
Monetary Economics, 43(1), 3-33.

Ayuso, J. and Restoy, F. (1996). Interest Rate Parity and Foreign Exchange Risk Premia in the ERM, Journal of International Money and Finance, 15(3), 369-382.

Baillie, R. and McMahon, P., (1985). Some Joint Tests of Market Efficiency: The Case of the Forward Premium, Journal of Macroeconomics, 7(1), 173-180.

Bekaert, G (1994). The Time-Variation of Risk and Return in Foreign Exchange Markets: A General Equilibrium Perspective, NBER Working Paper No 4818.

Bekaert, G. and Hodrick, R. (2000). Expectations Hypotheses Tests, NBER Working Paper No 7609.

Boughton, J., (1988). Exchange Rates and the Term Structure of Interest Rates, International Monetary Fund Staff Papers, 36-62.

Clarida, R. and Taylor, M. (1997). The Term Structure of the Forward Exchange Premiums and the Forecastibility of Spot Exchange Rates: Correcting the Errors, Review of Economics and Statistics, 79(3), 353-361.

Campbell, J. and Clarida, R. (1987). The Term Structure of Euromarket Interest Rates, Journal of Monetary Economics, 19(1) 25-44.

Canova, F. and Marrinan, J. (1993). Profits, Risk, and Uncertainty in Foreign Exchange Markets, Journal of Monetary Economics, 32(2) 259-286.

Cumby, R. (1988). Is It Risk? Explaining Deviations from Uncovered Interest Parity, Journal of Monetary Economics, 22(2) 279-299.

Drakos, K. (2001) Fixed Income Excess Returns and Time to Maturity, International Review of Financial Analysis, 10(4), pp. 431-442.

Drakos, K. (2003). The Term Structure of Deviations from The Interest Parity, Journal of International Financial Markets, Institutions and Money, 13(1), 57-67.

Engel, C., (1996). The Forward Discount Anomaly and the Risk Premium: A Survey on recent evidence, Journal of Empirical Finance, 3(2), 123-192.

Giovannini, A. (1980). The Deviations from Interest Rate Parity along the Term Structure of Forward Exchange Rates, Weltwirtschaftliches Archiv, 116, 225-234

Giovannini, A. and Jorion, P. (1989). Time-Variation of Risk and Return in the Foreign Exchange and Stock Markets, Journal of Finance, 44(2), 307-326.

Hettmansperger, T. (1984). Statistical Inference Based on Ranks, John Wiley and Sons, New York

Hicks, J. (1946). Value and Capital, Clarendon Press, London.

Ilmanen, A. (1995). Time-Varying Expected Returns in International Bond Markets, Journal of Finance, 50(2), 481-506.

Jorion, P. (1992). Term Premiums and the Integration of the Eurocurrency Markets", Journal of International Money and Finance, 11(1), 17-39.

Kaminsky, G. and Peruga, R., (1990). Can a Time-Varying Risk Premium Explain Excess Returns in the Forward Market for Foreign Exchange?, Journal of International Economics, 28(1-2), 47-70.

McCallum, B., (1994). A Reconsideration of the Uncovered Interest Parity Relationship, Journal of Monetary Economics, 33(1), 105-132. 
McCulloch, J. (1987). The Monotonicity of the Term Premium. A Closer Look, Journal of Financial Economics, 18(1), 185-192.

Mishkin, F. (1988). The Information in the Term Structure: Some Further Results, Journal of Applied Econometrics, 3(4), 307-314.

Mishkin, F. (1993). Money, Interest Rates and Inflation, Edward Elgar, England.

Nijman, T., Palm, F. and Wolff, C. (1993). Premia in Forward Foreign Exchange Rates as Unobserved Components: A Note, Journal of Business and Economic Statistics, 11(3), 361-365.

Porter, G., (1971). A Theoretical and Empirical Framework for Analysing the Term Structure of Exchange Rate Expectations, International Monetary Fund Staff Paper, 18, 642-664.

Richardson, M., Richardson, P. and Smith T. (1992). The Monotonicity of the Term Premium. Another Look, Journal of Financial Economics, 31(1), 97-105.

Solnik, B. (1993). The Performance of International Asset Allocation Strategies using Conditioning Information, Journal of Empirical Finance, 1(1), 33-55.

Svensson, L. (1993). Term, Inflation, and Foreign Exchange Risk Premia: A Unified Treatment, NBER Working Paper No 4544.

White, H., (1980). A Heteroskedasticity-Consistent Covariance Matrix Estimator and a Direct Test for Heteroskedasticity, Econometrica, 48(4), 817-838.

Wolff, C. (1987). Forward Foreign Exchange Rates, Expected Spot Rates, and Premia: A Signal-Extraction Approach, Journal of Finance, 42(2) 395-406. 